\title{
Bioethics Teaching and Assessment: My Experience of Three Institutes
}

\author{
Zoheb Rafique \\ Lecturer, Department of Biochemistry, \\ Liaquat University of Medical \& Health Sciences (LUMHS), Jamshoro, Pakistan \\ Email: dr zohaib@hotmail.com
}

\begin{abstract}
This paper describes my experience of teaching bioethics in different institutes and degree courses at undergraduate level. Bioethics is being taught to improve the understanding of the ethical issues in the field of medicine. The students are being trained in bioethics to recognize and resolve different ethical dilemmas and also to combat the situations where ethical analysis is needed. This paper also focuses on teaching and assessment methods for undergraduate courses.
\end{abstract}

Key Words: bioethics, teaching, assessment

Introduction: While few would deny the fact that some attention should be given to the ethical issues as part of a medical student's education, it has never been clear how this could be best achieved ${ }^{1}$. Bioethics is a necessary component of medical curriculum nowadays and it is being taught all over the world. It is not only included in medical curriculum, but also in dental, physiotherapy, nursing, biotechnology, residency programs and PhD Programs etc. The Edinburgh Declaration of Medical Education approved in 1988 requires that a future physician be trained as an attentive listener, a sensitive communicator, a careful observer and an effective clinician ${ }^{2}$. The practice of medicine is intrinsically an ethical enterprise because patients are vulnerable and suffering and medical treatments are not merely technical, they often invade patients' bodies and engage their consciences ${ }^{3}$. Pellegrino argues that the ethical decisions are an integral and essential part of being a good physician. The better the students' prior ethical education the better they can appreciate nuances and complexities of medical ethical choices. The less that prior education, the more the student needs instruction in ethics in the medical schools ${ }^{4}$. From the developing world, countries such as Pakistan, Sri Lanka, India and Saudi Arabia have been slow to respond to this universal need ${ }^{5-7}$. In Pakistan bioethics was started in 1998 at Aga Khan University (AKU) Karachi and was included in undergraduate curriculum of community health sciences ${ }^{8}$. In our university Liaquat University of Medical and Health Sciences Jamshoro (LUMHS), bioethics teaching was started in 2007 and was included in MBBS undergraduate curriculum. Bioethics is being taught in Lecture format only because of huge number of students and shortage of faculty, so we are not able to arrange problem based learning and small group discussions. I have been teaching bioethics to first year and second year MBBS Students since 2011. I have modified the curriculum and included more contemporary ethical issues and guidelines. Bioethics is not a separate subject in our MBBS program, but it a Tagged subject. 
One of the affiliated institutes at our university IPRS (Institute of Physiotherapy and Rehabilitation Sciences) has also started bioethics in their BSc Physiotherapy program. They included bioethics as a separate subject in their final year. I am teaching in IPRS along with their faculty. There are very few medical institutes in our city Hyderabad and one of them is ISRA University. I am working as a visiting faculty member in ISRA University and I am involved in teaching bioethics. I am teaching bioethics to first year MBBS students and they have included bioethics as a minor subject. In this Paper I will discuss my experience of teaching bioethics in these three institutes and I will also discuss the assessment methods in the exam.

How Do I Teach Bioethics: In our MBBS program at LUMHS, there are twelve lectures of bioethics in their curriculum. I use to take three lectures in each semester so I cover 12 lectures in the initial 4 semesters of MBBS. The main subjects in the initial two years are Anatomy, Physiology and Biochemistry and some of the other subjects are included as Tagged subjects. They include Bioethics, Information Technology and Community Medicine. Community Medicine becomes major subject in 4th year MBBS. The twelve lectures covers almost all major topic of bioethics and they include, Introduction to Bioethics, in which fundamental principles of bioethics and why there is need of bioethics, definition of ethics and bioethics, history of medical ethics and components of medical ethics are covered. Physician-Patient Relationship is included in which all the doctor-patient approaches are covered such as consumerist, paternalistic, relationship of mutuality and finally default approach. One more important topic of bioethics Confidentiality is also being taught in which definition of confidentiality, ethical basis of confidentiality, circumstances of breach of confidentiality, exceptions to the requirement of confidentiality, confidentiality in Research i.e. Benefits of maintaining confidentiality in Research, how confidentiality can be maintained in the Research setting and what Researchers should do in this regard are covered. Informed Consent, its definition, five components, why informed consent is necessary, who cannot give consent and when proxy has to sign consent form, informed consent when doing Research, informed consent form in detail are included. Euthanasia, its definition, types, examples, case scenarios, Islamic Teachings regarding Euthanasia and end of life issues are covered. Brief account of organ donation and abortion are also included. Medical error and its types, doctor guilt after making errors and strategies of avoiding medical errors and reporting them are also covered. One topic includes breaking bad news and why it is difficult to do it, ABCDE Mnemonic of breaking bad news and what are the things to be avoided while breaking bad news are taught. Professional ethics is also taught and it covers definition of professional ethics, the dual role of physician and investigator, ethical guidelines for research involving human subjects and Nuremberg code. Ethical Dilemma, its definition, types, why does it exist and what are the steps for resolving ethical dilemmas are covered. Privacy and Veracity are also in the curriculum and they cover definition of privacy, privacy types, definition of veracity and arguments contributing to the justification of obligations of veracity. Theories of bioethics are also included in the course ${ }^{9}$. One of the most important ethical issues which are often ignored is relationship of doctors/physicians with medical representatives of 
pharmaceutical companies and includes levels of interaction, promotions, various gifts from pharmaceutical companies, drug samples and its purpose in the eyes of patients, doctors and manufacturers. The curriculum at ISRA University is same as in LUMHS Jamshoro, but at ISRA University bioethics in being taught only in 2nd semester MBBS. Bioethics is major subject at IPRS LUMHS Jamshoro and it is being taught in their 7th and 8th semester (Final Year). I use to teach the same topics which I teach at MBBS level and they include all the topics from general ethics and they form the base of physiotherapy students. The IPRS have their own faculty also which is trained in ethics and they handle the ethical issues in the field of physiotherapy, organizational ethics and code of conduct in physiotherapy. We divided the topics into two and we cover them in both semesters (7th and 8th). As I earlier said in my paper that it is not possible for us to teach in any other format other than lectures, we do discuss case scenarios in our lectures and we make lectures interactive and we use power point presentations also in lectures. I always try to teach students the basic things so that they can learn and improve their future practices. The students do understand the ethical issues and they often ask questions regarding different ethical dilemmas.

How Do I Assess In Exam: My Bioethics topics are same for the three institutes but the difference comes when doing final assessment. At the end of the semester classes and before exams, I give them handouts of all the topics covered in the lectures. The assessment tool is summative assessment (exam at the end of semester ${ }^{10}$. In LUMHS MBBS Program there is no separate paper of bioethics, instead we give one compulsory short essay question in anatomy paper. Hence, anatomy paper consists of 95 marks and bioethics question contains 05 marks. If the students do not attempt the bioethics question they loss five marks because they don't have any choice as it is compulsory question. Due to the question being compulsory the students do read the handouts before the exam and generally they do perform well in exam. At ISRA University the subject as I said earlier is minor, but they do have full paper. The marks of the paper are included in the semester exam but not in final annual exam, as ISRA have both patterns of exam i.e., semester followed by annual. There is single paper which contains bioethics as well as skill. The skill here refers to skill lab procedures, methods and concepts and it is taught by the ISRA faculty themselves and I use to teach bioethics as visiting faculty member. The paper comprises of 100 marks with 50 marks reserved for each component i.e. bioethics and skill. There are 60 SBQs (Single Best Questions) and 8 SEQs (Short Essay Questions). Each (BCQ) best choice question (contain one mark and each SEQ contain five marks. The students have to secure 50 marks out of 100 to pass the subject. In BS Physiotherapy, the bioethics is compulsory subject and students have to pass the subject to clear their semesters. There is no annual system in IPRS so students have to clear bioethics in both 7 th and 8th semesters. There are 100 marks in bioethics paper and paper contains my component and other from the faculty of IPRS. We have again divided our portions and we teach in the ratio of 75:25. In 7th semester I teach 75 percent of the course and the IPRS faculty 25 percent. It is because the topics from general ethics helps the students and are like first step to understand ethical issues in physiotherapy in 
the coming lectures. In 8th semester the ratio inverses and I teach 25 percent of the curriculum and they teach 75 percent. The Physiotherapy component is mainly covered in 8th semester. There are 35 BCQs in the semester paper and contains 70 marks, while 30 marks are reserved for SEQs and students have to attempt 6 questions out of 8 and each question carries 05 marks. We have the paper distribution also in the ratio of 75:25, in which 6 SEQs and $27 \mathrm{BCQs}$ are given to 75 percent weightage component and 2 SEQs and $08 \mathrm{BCQs}$ are reserved for 25 percent component and vice versa in other semester. In BCQs we include some case scenarios also which are discussed in the lectures. Those students who get less than 50 percent marks are declared fail and they have to appear in Re-sit exam. The performance of Physiotherapy students is better than MBBS Students in the exam. This is because bioethics is included in their final year and they are already familiar with the clinical subjects and clinical ward postings and being final year students their maturity and cognitive level is also higher than 1st year MBBS Students. The other reason is that they have compulsory subject of bioethics and they have to pass it at any cost to get the degree. The time allotted for papers is 2 hours in physiotherapy paper and 2 and half hours in MBBS paper at ISRA University and LUMHS Anatomy paper is also of 2 hours where one compulsory question of bioethics is included. There is no OSPE or OSCE exam included to assess the students. The students' attendance is merged and counted in overall attendance with other major subjects and those students who have less than 75 percent attendance are not allowed to appear in exam. This rule applies to all three institutes uniformly. Some students take bioethics seriously and try to understand the concepts and contemporary issues in the field, while other just tries to pass the exam and show superficial interest.

Conclusion: A good physician is one who is not only technically sound, but also ethically well-grounded. Medical institutes in Pakistan are providing technical training, but largely neglecting the ethical component. Given the challenging environment of developing countries, it is imperative that structured education in bioethics with a proper evaluation and feedback system is developed. Bioethics is currently being taught in almost all major medical institutes of our country and the smaller and newer institutes should also adopt this strategy. My current experience of almost 2 and half years of teaching bioethics is satisfactory and I hope the future generation of the doctors will practice their medicine in ethical way and they will implement bioethics in their clinical practices and research, whether it is informed consent or keeping confidentiality of the patient and the research subjects or avoiding unethical relationship with the representatives of the pharmaceutical companies.

\section{References:}

1. D J Weatherall. Teaching ethics to medical students. Journal of medical ethics.1995 21: 133-134

2. The Edinburgh Declaration. The world conference on medical education. 1988 August 7-12. Edinburgh, Scotland: World Federation for Medical Education.

3. Dubois JM, Burkemper J. Ethics education in US medical schools: A study of syllabi. Acad Med. 2002 $77: 432-437$. 
4. Pellegrino ED. Teaching medical ethics: Some persistent questions and some responses. Acad Med. 1989 64:701-703.

5. Al-Shehri MY. Medical curriculum in Saudi medical colleges: Current and future perspectives. Ann Saudi Med. 2001 21:320-323.

6. Shiraz B, Shamim MS, Shamim MS, Ahmed A. Medical ethics in surgical wards: Knowledge, attitude and practice of surgical team members in Karachi. Indian J Med Ethics. 2005 2:94-96.

7. Al-Umran KU, Al-Shaikh BA, Al-Awary BH, Al-Rubaish AM, Al-Muhanna FA. Medical ethics and tomorrow's physicians: An aspect of coverage in the formal curriculum. Med Teach. 2006 28:182-184.

8. KULSOOM GHIAS, SYEDA KAUSER ALI, KAUSAR S. KHAN, ROBYNA KHAN, MURAD M. KHAN, ARSHI FAROOQUI \& PARVEZ NAYANI. How we developed a bioethics theme in an undergraduate medical curriculum. Med Teach. 2011 33: 974-977.

9. Tom L. Beauchamp, James F. Childress. Principles of Biomedical Ethics. 2001; 5th edition, Oxford University Press.

10. K Mattick, J Bingh. Teaching and assessing medical ethics: where are we now? J. Med. Ethics. 2006 32:181-185.

Conflict of interest: There is no conflict of interest. 